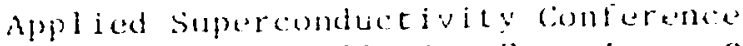

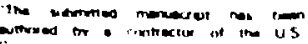
(i)

\title{
INFLUENCE OF DUMP VOLTAGE AND ALLOWABLE TEMPERATURE RISE ON STA BILIZER REQUIREMENTS IN SUPERCONDUCTING COILS*
}

\author{
S. W. Schwenterly \\ Oak Ridge National Laboratory, P.O. Box 2009 \\ Oak Ridge, TN $37831-8054$
}

CONF-880812--18

DE89 001684

\begin{abstract}
A superconducting winding must have enough stabilizer to satisfy two sets of criteria. During normal operation, the amount of stabilizer must be large enough either to make the coil unconditionally stable or to give a certain desired stability margin. Once a dump occurs, the amount of stabilizer must be large enough to carry the current without generating excessive dump voltages or allowing the winding to exceed a certain maximum temperature (and maximum pressure, in the case of force-cooled coils). The voltage criterion often dominates for very large coil systems, but it is frequently ignored in initial derign studies. This paper gives some simple relations between the dump voltage and the stored energy, temperature rise, and coil geometry that are useful in scoping the required amount of stabilizer. Comparison with some recently proposed fusion magnet system designs indicates that excessive dump voltages could result in some cases. High-temperature superconductors may require more stabilizer than the conventional alloys. Calculations with simple model coil systems indicate how trade-offs b : ween various coil parameters affect the dump voltage.
\end{abstract}

\section{Introduction}

When a superconducting winding develops a steady or growing normal zone, the current must be quickly interrupted to prevent excessive heat generation in the conductor. The stored energy can be dissipated completely in the winding itself; however, this requires that the entire winding be reliably driven normal to avoid localized hot spots. More frequently, the energy is dissipated in external dump resistors at room temperature. The disadvantage of this approach is that high voltages may be required to remove a large enough fraction of the er. ergy. To prevent costly modifications late in the design cycle, space for electrical insulation should be fully considered at the start of conceptual design. In this initial design phase, simple relations between the dump voltage and the coil and conductor parameters are useful in choosing practical alternatives from the many possible combinations. Using simplified model coil geometries, one can derive closed-form relations that give information about the general effects of various parameters on the dump voltage. More sophisticated models can then be used to refine the results.

\section{Relation of Dump Voltage to Stored Energy and Final Temperature}

Once the shape, size, and magnetic field distribution in the volume surrounded by the magnet have been determined, the stored energy $E$ and the ampere-turns $N I$ are also fixed. Suppose that a normal zone of resistance $r(T)$ and length $\ell_{n}$ develops and that the magnet is then dumped immediately into an external resistance $R_{d} \gg r$. If heat transfer oul of the normal zone is assumed to be negligible, the maximum heating will occur. Then a sruall change $d E$ in the stored energy is related to a temperat i. rise $d T$ in the conductor by

$$
\frac{r(T)}{R_{d}} d E=v C(T) d T .
$$

\footnotetext{
-Research eponsored by the Office of Fusion Energy, U.S. Department of Energy, under contract DE-AC05-840R21400 with Martin Marietta Energy Systems, Inc.
}

Manuscript received August 22, 1988
(All variables are defined in the list at the end of the paper.) If desired, $C$ can be corrected straightforwardly for the contributions of the superconductor and any structure in intimate thermal contact with the stabilizer. Since $v=\ell_{n} a_{c}$ and $r=\rho \ell_{n} / a_{e}$, this leads to

$$
R_{d} \int_{T_{i}}^{T_{f}} \frac{C(T)}{\rho(T)} d T=R_{d} H\left(T_{f}\right)=\frac{E}{a_{c}^{2}}
$$

$H$ is the familiar "hot spot integral," and the subscripts on $T$ denote the initial and final temperatures of the conductor during the dump. Note that the length of the initial normal zone drops out of the calculation. The normal zone may grow during the dump; however, if heat transfer along the conductor is neglected, any areas that go normal later in the dump will receive a smaller portion of the stored energy and will not reach as high a temperature. The final temperature of the initial normal zone is not affected, as long as the total normal resistance is much less than $R_{d}$.

Since $R_{d}=V / I$ and $a_{c}=A / N$, the dump voltage needed to give a final temperature of $T_{f}$ is

$$
V=[N I E] \frac{N}{A^{2} H\left(T_{S}\right)}
$$

Here $A$ is the total area of stabilizer in all $N$ turns of the winding pack, exclusive of coolant and electrical insulation. The quantity $N I E$ is a constant, and once the stabilizer material is chosen the dump voltage can be affected only by varying the maximum allowable $T, N$, and particularly $A$. In many applications, both space limitations and economic factors create pressure to reduce the winding cross section. However, attempts to increase the current density in the windil: $g$ pack by reducing $A$ must be made cautiously, because the dump voltage increases rapidly.

\section{Dump Voltage in Simple Coil Geometries}

Application of (3) requires estimates of $E$ and $N I$ for the proposed coil array. $N I$ can be found from the required field with Ampère's law, $\oint \vec{B} \cdot \overrightarrow{d l}=\mu_{0} N I$, and $E$ can be determined from the calculated inductance using $E=\frac{1}{2} L I^{2}$. In this section, simple models are used to generate approximate values for these quantities and corresponding approximate relations for the dump voltage are given.

\section{Solenoid}

The simplest example that might be considered is a section of length $\ell$, in an infinitely long single-layer solenoid of radius a. Assume that this section contains $N$ turns and is connected across its own dump resistor so that it generates a voltage $V$ during a dump. The field is uniform inside the solenoid and zero outside. The ampere-turns are thus related to the ficld by

$$
N I=\frac{\ell, B}{\mu_{0}}
$$

The stored energy is

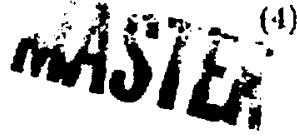

$E=\frac{1}{2} L I^{2}=\frac{\mu_{0} \pi a^{2} N^{2} I^{2}}{2 \ell_{1}}$ 
Substituting for $N I$ and $E$ in $(3 j$, we have

$$
V=\left[\frac{\pi a^{2} \ell_{0}^{2} B^{3}}{2 \mu_{0}^{2}}\right] \frac{N}{A^{2} H\left(T_{f}\right)}
$$

The dump voltage thus depends most strongly on the required magnetic field, as well as the dimensions of the volume surrounded by the winding. For short multilayer coils, a geometric correction factor must be added to (5) and (6), but the dependence on the various parameters is unchanged. Formulas for calculation of the inductance of short solenoids can be found in Refs. 1 and 2.

\section{Toroid}

Toroidal coil sets are of particular interest in fusion reactor applications. Assume that the radial thickness of the winding pack is much less than $a$, so that the coil can be treated as a single layer. For situations where the major radius $R$ is comparable to $a$, the field inside the toroid falls off inversely with the diatance from the major axis. $N I$ is given by

$$
N I=\frac{2 \pi R B}{\mu_{0}},
$$

where $B$ is now defined as the value at radius $R$, and the inductance $^{1,2}$ is

$$
L=\mu_{0} N^{2}\left(R-\sqrt{R^{2}-a^{2}}\right) .
$$

The dump voltage is then

$$
V=\left[\frac{4 \pi^{3} R^{3} B^{3}}{\mu_{0}^{2}}\left(R-\sqrt{R^{2}-a^{2}}\right)\right] \frac{N}{A^{2} H\left(T_{f}\right)}
$$

In many situations, the turns are oval or D-ahaped rather than circular. This can be simulated using a toroid with rectangular turns. If each turn has height $h$ and width $2 a$ (see Fig. 1), the inductance ${ }^{1,2}$ is

$$
L=\frac{\mu_{0} N^{2}}{2 \pi} h \ln \left(\frac{R+a}{R-a}\right) .
$$

Since the field in the toroid drops off inversely with radius no matter what the turn shape is, we can combine the stored energies from (8) and (10) to obtain the stored energy of a toroid with "racetrack" coil having vertical straight sections of height $h$ and upper and lower circular sections of radius $a$, as shown in Fig. 1. The dump voltage is

$V=$

$\frac{4 \pi^{3} R^{3} B^{3}}{\mu_{0}^{2}}\left[\frac{h}{2 \pi} \ln \left(\frac{R+a}{R-a}\right)+\left(R-\sqrt{R^{2}-a^{2}}\right)\right] \frac{N}{A^{2} H\left(T_{f}\right)}$.

\section{Dump Voltage in Proposed Eusion Renctor Designs}

A number of fusion reactor designs incorporating very large toroidal field coils have been proposed in recent years. These include the Tokmak Fusion Core Experiment ${ }^{3}$ (TFCX), the Tokamak Ignition/Burn Engineering Reactor* (TIBER II), the International Thermonuclear Experimental Reactor ${ }^{5}$ (ITER), the Advanced Stellarator Reactor (ASR) design, and the STARFIRE designs. ${ }^{7,3}$ These large coil arrays have high stored energy, so that care must be taken to provide enough stabilizer to allow dumping the coils without excessive voltege or temperature rise. Table 1 summarizes the relevant coil parameters from some of these atudies ${ }^{3-1}$ and gives dump voltages calculated with (9) or (11) as appropriate. Also shown are the nominal dump roltages given in some of the studies. The first four entriea use a force-cooled cable-in-conduit conductor (CICC)

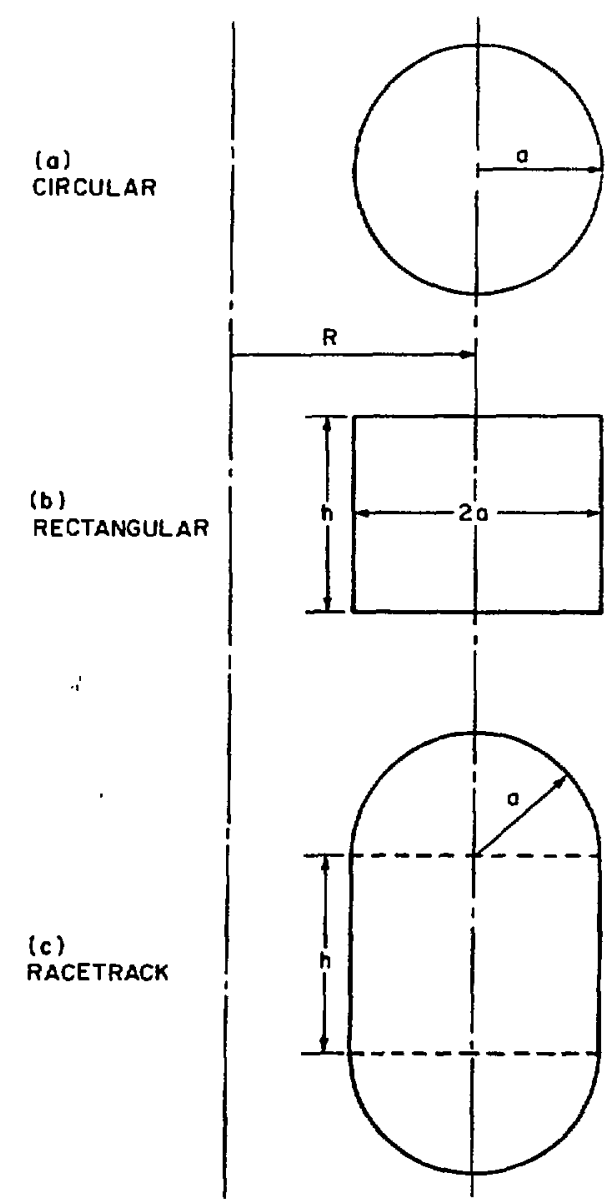

Fig. 1. Toroidal coil geometries. oimilar to that used in the Westinghouse coil for the Large Coil Task (LCT). STARFIRE uses a pool-boiling Rutherford cable conductor in a perforated stajnless steel sheath. The last entry is a follow-up study to STARFIRE that uses a high-temperature ceramic superconductor and liquid nitrogen cooling. All the coils are D-shaped, except for those of the ASRA6B stellarator. The ASRA6B stellarator coils are modular and nonplanar, but they are roughly circular when viewed from the side.

The value of the hot-spot integral $H\left(T_{J}\right)$ was calculated under the assumption that the copper residual resistivity was increased by radiation damage to the saturation value of $3.5 \mathrm{n} \Omega \cdot \mathrm{m}$. The heat capacity was corrected by adding a contribution for the superconductor and stainless steel sheath. This had the effect of roughly doubling the contribution of the copper alone. ${ }^{10}$ The heat capacity of the coolant was not included. Two values were calculated: for a final conductor temperature of $100 \mathrm{~K}, H\left(T_{f}\right)=4.6 \times 10^{16} \mathrm{~J} \cdot \Omega^{-1} \cdot \mathrm{m}^{-4}$; for $150 \mathrm{~K}$, $H\left(T_{f}\right)=7.6 \times 10^{10} \mathrm{~J} \cdot \Omega^{-1} \cdot \mathrm{m}^{-1}$. For the STARFIRE study less radiation damage was assumed, and the corresponding values of $H\left(T_{l}\right)$ were increased to $1.0 \times 10^{17}$ and $1.3 \times 10^{17} \mathrm{~J} \cdot \Omega^{-1} \cdot \mathrm{m}^{-4}$.

In all cases it was found that the voltage would be much too high to dump the entire array of coils in series on one dump resistor. Table 1 thus shows voltages per coil, on the assumption that each coil is dumped into its own resistor. If there are $n$ coilo in the array, then the stored energy and dump voltage per coil are both reduced by the factor $n$. 
Tabl. : Calculated dump veltages for sarious proposed fusion reactor toroidal foil designs.

\begin{tabular}{|c|c|c|c|c|c|c|c|c|c|c|}
\hline Machine & $\begin{array}{c}B \\
(\mathrm{~T}) \\
\end{array}$ & $\stackrel{R}{(m)}$ & $\begin{array}{c}a \\
(\mathrm{in})\end{array}$ & $\begin{array}{c}h \\
(\mathrm{~m})\end{array}$ & $N$ & $n$ & $\left(m^{2}\right)$ & $\begin{array}{l}\text { Voltiage } \\
\text { at log ḱ } \\
\text { (kVicoil) }\end{array}$ & $\begin{array}{l}\text { Virltage } \\
\text { at } 150 \mathrm{~K} \\
(\mathrm{kV} / \mathrm{coil})\end{array}$ & $\begin{array}{l}\text { Nominal } \\
\text { dump voltage } \\
\text { (kV/coil) }\end{array}$ \\
\hline $\mathrm{TFCX}^{3}$ & $4.3^{a}$ & 3.4 & 2.2 & 2.1 & 4,128 & 16 & 0.411 & 9.3 & 5.7 & $3(200 k)$ \\
\hline TIBER II' & 6.0 & 3.0 & 2.0 & 2.0 & 2,560 & 16 & 0.42 & 11.5 & 7.0 & $10(130 \mathrm{~K})$ \\
\hline l'TER ${ }^{5}$ & 5.1 & 5.8 & 3.7 & 4.6 & 4,576 & 16 & 1.24 & 20.0 & 12.1 & 20 \\
\hline ASRA6B Stell." & 5.3 & 25.0 & 5.2 & - & 37,500 & 30 & 9.13 & 32.8 & 19.9 & - \\
\hline STARFIRE ${ }^{\top}$ (Gr. I) & $5.8^{b}$ & 8.1 & 4.9 & 4.3 & 8,458 & 12 & 5.84 & $2.8^{c}$ & $2.2^{d}$ & $2.5(100 \mathrm{~K})$ \\
\hline STARFIRE $^{\top}$ (Gr. IV) & $5.8^{b}$ & 8.1 & 4.9 & 4.3 & 8,458 & 12 & 3.16 & $8.1^{c}$ & $6.2^{d}$ & $2.5(100 \mathrm{~K})$ \\
\hline STARFIRE-CSC & $5.8^{b}$ & 8.1 & 4.9 & 4.3 & 8,158 & 12 & $5 .(0)$ & 31.4 & 8.9 & - \\
\hline & $5.8^{b}$ & 8.1 & 4.9 & 4.3 & 8,458 & 12 & 1.01 & 790 & 226 & \\
\hline & $5.8^{b}$ & 8.1 & 4.9 & 4.3 & 8,458 & 12 & 2.0 & 201 & 58 & \\
\hline & $5.8^{b}$ & 8.1 & 4.9 & 4.3 & 8,458 & 12 & 1.2 & 560 & 160 & - \\
\hline
\end{tabular}

\section{Discussion}

The calculated voltages range widely, from less than $4 \mathrm{kV}$ to nearly $800 \mathrm{kV}$. This leads to the question of what is a "reasonable" dump voltage. The coil insulation should be able to withstand a hi-pot test at two to four times the operating rolt. age to ensure that any contamination that might get in during operation will not trigger a breakdown. "In forced-flow designs, most of the insulation is outside the conductor and sealed off from the coolant stream. The only vulnerable spots are at the electrical breaks in the coolant feed tubes, and these can be made accessible for cleaning or replacement. However, in poolboiling designs, all of the electrical insulation is exposed to the coolant flow, and failures deep in the winding pack are impossible to repair. Therefore, pool-boiling coils ought to be tested at afety factors eloser to four, while factors of two would probably be adequate for forced-flow coils. It is the author's experience that the difficulty, danger, and expense of hi-pot testing begin to increase rapidly above test voltages of about $50 \mathrm{kV}$. Thus, at least for the first reactors, dump voltages for pool-boiling coils ought to be limited to about $12 \mathrm{kV}$, and those for forced-flow coils to about $25 \mathrm{kV}$.

By this criterion, the dump voltages for TFCX, TIBER II, ITER, and STARFIRE all look reasonable. It should be noted that the current strategy for ITER is to limit the dump voltage to $20 \mathrm{kV}$ and then calculate the proper amount of stabilizer to give this value; this was done for the ITER entry in Table 1. If the maximum temperature is increased to $150 \mathrm{~K}$, the dump voltage drops by the ratio $H(100 \mathrm{~K}) / H(150 \mathrm{~K})=0.6$. Alternatively, the dump voltage could be kept the same and the stabilizer area could be reduced by the factor $\sqrt{0.6}$. The stellarator dump voltage for $100 \mathrm{~K}$ final temperature is too high, mainly because of the very large number of turns in the coils. The voltage could be reduced easily by increasing the conductor area and current to reduce the number of turns. If this leads to too much conductor strain because of the small bending radii needed for modular stellarator coils, pairs of smaller conduclors might instead be wound in parallel. An extra advantage of this scheme would be the possibility of connecting parallel conductors in a bridge circuit for quench detection.

The STARFIRE study used four different grades of conductor. In this case, an effective value of $A$ was calculated assuming that all turns in the coil had the same stabilizer area as the conductor grade where the hot spot occurred. 'T'his was required because of the assumption $A=N a_{r}$ used to derive (3). As long as the hot spot remains in only one grade, the results are correct, because current fows only in the superconductor in the rest of the coil. The voltages given in '('able 1 are for the Grade-I (high field) and Grade-IV (low field) S'TARFIRF, conductors.
The STARFIRE CSC study was performed to investigate the econornic advantages of using the recently discovered hightemperature ceramic superconductor (CSC) in commercial fusion reactor magnets cooled by liquid nitrogen. Because of the high heat capacity of the copper stabilizer at $77 \mathrm{~K}$, very large heat pulses can be absorbed without much temperature rise in the conductor. This offers the possibility of greatly reduced stabilizer area compared with low-temperature superconductors. In this study, four cryostable conductors with varying amounts of copper and superconductor were considered, leading to the four different total stabilizer areas shown in Table 1. Dump voltages for these designs are much higher than those for the low-temperature STARFIRE, however. Even the design with the lowest current density and over $5 \mathrm{~m}^{2}$ of copper has several times the STARFIRE dump voltage, and the other designs give dump voltages far too high for practical design and operation. The reason for this is that $H\left(T_{f}\right)$ is greatly reduced with operation at $77 \mathrm{~K}$. Coils with high-temperature CSC are subject to the same constraints on thermal expansion and final temperature as those with low-temperature conductor. Thus, the integral is taken only from the CSC critical temperature, say $90 \mathrm{~K}$, to the maximum temperature of $100 \mathrm{~K}$ or $150 \mathrm{~K}$. A ppropriate values of the hot-spot integral for high-temperature CSC are $H(100 \mathrm{~K})=1.2 \times 10^{16}$ and $H(150 \mathrm{~K})=4.2 \times 10^{16} \mathrm{~J} \cdot \Omega^{-1} \cdot \mathrm{m}^{-4}$. Hence, even if the magnet dimensions and stabilizer area are kept the same, the dump voltage with high-temperature CSC will be much higher.

As shown in the last column of Table 1 , the dump voltages calculated here agree reasonably well with most of the nomnal dump voltages quoted by the authors of the various reactor studies. The nominal STARFIRE dump voltage agrees well with the value calculated here for the Grade-l conductor. However, the Grade IV dump voltage is much higher, and a quench in the Grade-IV conductor would lead to scrious overheating if a dump voltage of only $2.5 \mathrm{kV}$ were used. The need for higher dump voltages to protect the low-grade conductor is a disadvantage for grading which seems not to have been recognized previously.

For pool-boiling designs, the adiabatic assumption is too conservative, so that about half the Joule heat generated in the hot spot goes into the helium or neighboring conductor. This is supported by the results reported by lue ${ }^{2}$ of hot-spot measurements on the General Electric I.C'I coil. The measured maxinum temperature in a dump from $100 \%$ current was sinly $40 \mathrm{~K}$, compared with $95 \mathrm{~K}$ calculated with the adiabalic assumption. However, hot-spot neeasurements on the Westinghouse LC'T coil indicated that the adiabatic assumption gives a fair and reasmably conservative estimate of the maximum temperature for furced-flow conductors. ${ }^{12}$ 
The relations used to calculate stored energy assume that the loroid has a single layer of turns that are evenly distributed, so application to tokamaks with 12 or 16 discrete coils neglects the effect of ripple. The stored energy calculated with the inductance derived from (8) and (10) is about $35 \%$ higher than the 50-GJ figure quoted by the STARFIRE study, but it is not clear how accurately the stored energy calculations were done in any of the studies.

\section{Conclusions}

Simple relations have been derived that give reasonably accurate estimates of the dump voltage for toroidal coil arrays. Because of the dependence of the dump voltage on $R, B^{3}$, and $A^{-2}$, stabilizer areas must be chosen carefully as the major radius and field are scaled up. Application to several recent reactor studies indicates the following:

- Large reactor-scale tokamak coils using conventional superconductors can be dumped at voltages that appear practical for design and operation.

- The adiabatic assumption leads to dump voltages that are about right for forced-flow coils but are roughly twice the appropriate values for puol-boiling coils. Since higher safety factors appear advisable for pool-boiling coils, both types ought to be designed to be tested at twice the voltage calculated from the relations given here.

- Very large stellarators $(R \sim 25 \mathrm{~m})$ can be designed to dump at reasonable voltages per coil, but the number of turns may have to be limited by using large conductor or several small conductors wound in parallel.

- It may be difficult to take advantage of the high stability margins offered by high-temperature CSC without giving up the ability to rapidly dump the coils at reasonable voltages, owing to the reduced value of the hot-spot integral with this material.

\section{References}

[1] F. W. Grover, Inductance Calculations-Warking Formulas and Tables. New York: Dover, 1962.

[2] F. E. Terman, Radia Engineers' Handbook. New York: McGraw-Hill, 1943.

[3] J. R. Miller, "Design of aggressive superconduciing TFCX magnet systems," Fusion Technol., vol. 8, pp. 829-837, July 1985 .

[4] J. R. Miller et al., "High current density magnets for INTOR and TIBER," presented at the INTOR Workshop, Vienna, A ustria, December 1-13, 1986.

[5] Latest ITER parameters, communicated by J. D. Galambos, Fusion Engineering Design Cenler, Oak Ridge, Tn.
(6) G. Böhme el al, "Studies of a modular advanced stellarator reactor ASRA6C," Report FPA-87-2, Fusion Power Associales, Madison, WI, May 1987.

[7] C. C. Baker et al., "STARFIRE-A commercial tokamak fusion power plant study," Report ANL/FPP-80-1, Argonne National Laboratory, Argonne, IL, September 1980.

[8] D. A. Ehst et al., "Application of high temperature ceramic superconductors (CSC) to commercial tokamak reactors," Report ANL/FPP/TM-214, Argonne National Laboralory, Argonne, IL, October 1987.

[9] C. J. Heyne et al., "Westinghouse design of a forced-flow $\mathrm{Nb}_{3} \mathrm{~S} n$ test coil for the Large Coil Program," in Proceedings of the Bth Symposium on Engineering Problems of Fusion Research, San Francisco, CA, November 13-16, 1979, pp. 1148-1153.

[10] L. Dresner, "Quench pressure, thermal expulsion, and normal zone propagation in internally cooled superconductors," presented at Applied Superconductivity Conference, San Francisco, GA, August 21-25, 1988.

[11] S. W. Schwenterly, "Design and testing of electrical insulation for superconducting coils," Advances in Cryogenic Engineering, vol. 33, pp. 271-281, 1988.

[12] J. W. Lue et al., "Hot-spot mensurernents on the U.S.LCT coils in the IFSMTF," presented at the 12th Symposium on Fusion Engineering, Monterey, CA, October 12-16, 1987.

\section{List of Variables}

$\begin{aligned} A & \text { total stabilizer area of all } N \text { turns in winding } \\ a & \text { solenoid radius or toroid minor radius } \\ a_{e} & \text { stabilizer area in a single turn } \\ C(T) & \text { stabilizer volume specific heat capacity } \\ E & \text { stored energy of winding } \\ H\left(T_{f}\right) & \text { hot spot integral } \\ h & \text { height of a toroid with rectangular turns } \\ I & \text { winding current } \\ L & \text { inductance } \\ \ell_{n} & \text { length of initial normal zone } \\ \ell_{b} & \text { length of solenoid } \\ N & \text { number of turns in winding } \\ n & \text { number of toroidal field coils in reactor } \\ R & \text { toroid major radius } \\ R_{d} & \text { dump resistance } \\ r(T) & \text { resistance of normal zone } \\ \rho(T) & \text { resistivity of stabilizer } \\ T & \text { temperature of normal zone } \\ v & \text { volume of normal zone }\end{aligned}$

\section{DISCLAIMER}

This report was prepared as an account of work sponsored by an agency of the United States Government. Neither the United Stales Government nor any agency thereof, nor any of their employees, makes any warranty, express or implied, or assumes any legal liability or responsibility for the accuracy, completeness, or usefulness of any information, apparatus, product, or process disclosed, or represents that its use would not infringe privately owned rights. Reference herein to any specific commercial product, process, or service by trade name, trademark, manufacturer, or otherwise does not necessarily constitute or imply its endorsement, recommendation, or favorilig by the United States Government or any agency thereof. The views and opinions of authors expressed herein do not necessarily state or reflect those of the Unitod Stales Government or any agency thereof. 